\title{
Weight Loss and the Older Adult: Risks and Benefits ${ }^{1}$
}

\author{
Wendy Gans, Rachelle Savelle, Nancy J. Gal, and Wendy Dahl²
}

Adults who are obese are often advised to lose weight to reduce the risk of chronic disease (Jensen et al. 2014). However, the health benefits of weight loss change as we become older (DiMilia, Mittman, and Batsis 2019). This publication discusses the risks and benefits of planned and unplanned weight loss for older adults.

Obesity is associated with higher risk of many chronic diseases, including heart disease and type 2 diabetes. Weight loss may reduce the risk of developing chronic diseases and conditions and improve quality of life (Leslie and Hankey 2015). Weight loss may also make it easier to be physically active. However, the "obesity paradox" describes the observations that some excess weight may serve a protective role for older adults, but the relationships between weight status and health risks are complex (Bosello and Vanzo 2019). Although obesity is associated with improved survival of serious illnesses (Toft-Petersen et al. 2018), obese older adults with low muscle mass are at higher risk for poor outcomes during and after critical illness (Tieland, van Dronkelaar, and Boirie 2019). Obesity may delay stroke recovery (Kalichman, Alperovitch-Najenson, and Treger 2016), but in contrast, it improves recovery following hip fracture (Nishioka et al. 2020)
Obesity is defined as a body mass index (BMI), a ratio of height to body weight, of greater than 30 . The BMI range with the lowest mortality (risk of death) includes higher BMls for older adults compared to younger adults. This suggests older adults may benefit from slightly higher body weights than younger adults (Bhaskaran et al. 2018). See the following link to calculate your BMI. https:// www.nhlbi.nih.gov/health/educational/lose_wt/BMI/bmicalc.htm

\section{Is weight loss planned or unplanned?}

Whether weight loss is planned or unplanned is an important consideration for an obese older adult. Unplanned weight loss, referred to as unintentional weight loss, is linked to health risks. Unintentional weight loss from midlife to later life is associated with mild cognitive impairment (Alhurani et al. 2016). In older women, unintentional weight loss is associated with an increased risk of fracture (Compston et al. 2016). Unintentional weight loss is also associated with functional decline (Ritchie et al. 2008) and, when combined with low muscle mass, is related to a poor quality of life in community-dwelling older adults (Kim, Kim, and Won 2018). Significant unplanned weight loss may affect survival (Cao, Hardy, and Wulaningsih 2019).

\section{Case Study}

Susan is your 79-year-old neighbor. When you told her that she looked like she had lost some weight, she happily replied with, "Yes, I've lost almost 15 pounds!" Susan has been overweight for most of her life and obese for the past 15 years. Is Susan's recent weight loss a good thing?

1. This document is FSHN20-42, one of a series of the Food Science and Human Nutrition Department, UF/IFAS Extension. Original publication date September 2020. Visit the EDIS website at https://edis.ifas.ufl.edu for the currently supported version of this publication.

2. Wendy Gans, former MS-DI student; Rachelle Savelle, former MS-DI student, Food Science and Human Nutrition Department; Nancy J. Gal, Extension agent emeritus, Food and Consumer Sciences, UF/IFAS Extension Marion County; and Wendy Dahl, associate professor, Food Science and Human Nutrition Department; UF/IFAS Extension; Gainesville, FL 32611.

The Institute of Food and Agricultural Sciences (IFAS) is an Equal Opportunity Institution authorized to provide research, educational information and other services

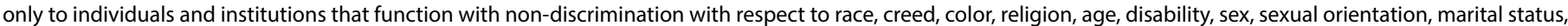

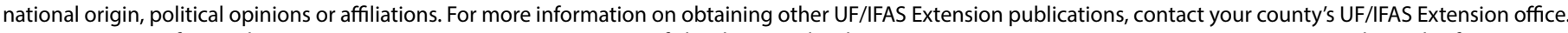
U.S. Department of Agriculture, UF/IFAS Extension Service, University of Florida, IFAS, Florida A \& M University Cooperative Extension Program, and Boards of County Commissioners Cooperating. Nick T. Place, dean for UF/IFAS Extension. 


\section{Why is unintentional weight loss common in older adults?}

Unintentional weight loss is often due to reduced food intake resulting from lack of appetite. Lack of appetite may be the result of disease conditions, medications, loneliness, or depression (Gaddey and Holder 2014). Chewing and swallowing difficulties due to dry mouth, medications, or conditions such as stroke, dementia, or neuromuscular disease may also lead to reduced food intake and unintentional weight loss (Christmas and Rogus-Pulia 2019). Consuming a texture-modified diet may help to maintain safe swallowing and food intake but may decrease quality of life (Swan et al. 2015). Other barriers to adequate food intake in older adults may include lack of finances to purchase enough nutritious foods and difficulties with shopping or preparing food.

If an older adult is unintentionally losing weight, he or she should visit a healthcare professional to determine the cause of the weight loss and how to address it. It is very important for older adults to follow up with their health care provider because the weight loss may be due to an undiagnosed disease such as cancer (Bosch et al. 2017).

\section{What can be done to avoid unintentional weight loss?}

It is important for older adults to enjoy a high quality of life, remain able to perform activities of daily living, and maintain their independence. When unintentional weight loss occurs, older adults and their health care team should develop strategies to identify and manage issues related to the unintentional weight loss. A comprehensive team of health professionals may include a dietitian, physician, occupational therapist, physical therapist, speech-language pathologist, dentist, and social worker. Nutrition and lifestyle adaptions may improve dietary intake and prevent further unintentional weight loss. Below are some tips to help prevent unintentional weight loss, especially muscle loss.

Tips for managing unintentional weight loss:

- Consume adequate calories to meet energy needs

- Consume more high-protein foods such as meat, poultry, seafood, eggs, and dairy

- Consume more plant-based proteins such as soy, legumes, nuts, and seeds

- Replace low-fat dairy with full-fat dairy foods

- Consume snacks or nutritional supplements between meals

- Discuss any chewing and swallowing problems with your health care provider

- Discuss the risks and benefits of any diet restrictions with your health care provider

The registered dietitian nutritionist (RDNs) is the nutrition specialist on the health care team. For older adults, RDNs provide a vital service by providing medical nutrition therapies necessary to manage existing health conditions. RDNs help promote optimal nutrition to avoid unintentional weight loss and improve quality of life.

\section{Intentional Weight Loss}

Planned weight loss may have benefits for some older adults (Wannamethee, Shaper, and Lennon 2005). If an older adult with obesity plans to lose weight, it should be done under the supervision of a health care provider. The safest and most effective way to lose weight is by combining a healthy eating pattern and a physician-approved exercise program. This will lead to increased cardiovascular fitness, muscle strength, and lean body mass, while minimizing the risk of malnutrition that can happen from reducing calories. Weight loss should not be pursued unsafely by eliminating food groups or following a fad diet. Weight loss is best achieved gradually with the individual's overall health and quality of life as priority. Always consult with your health care provider before beginning a diet or physical activity program. The following website provides reliable information on physical activity and aging: https://www.nia.nih. gov/health/exercise-physical-activity.

So, should Susan be congratulated for her weight loss? It is important to determine whether Susan's weight loss was unintentional or planned. In either case, Susan should see her health care provider and come up with a plan to minimize any potential health risks related to weight loss. At the end of the day, Susan should focus on a healthful lifestyle that improves her overal wellness.

\section{References}

Alhurani, R. E., M. Vassilaki, J. A. Aakre, M. M. Mielke, W. K. Kremers, M. M. Machulda, Y. E. Geda, D. S. Knopman, R. C. Petersen, and R. O. Roberts. 2016. "Decline in Weight and Incident Mild Cognitive Impairment: Mayo Clinic Study of Aging." JAMA Neurol 73 (4): 439-46. doi: 10.1001/ jamaneurol.2015.4756.

Bhaskaran, K., I. Dos-Santos-Silva, D. A. Leon, I. J. Douglas, and L. Smeeth. 2018. "Association of BMI with Overall and Cause-Specific Mortality: A Population-Based 
Cohort Study of 3.6 Million Adults in the UK." Lancet Diabetes Endocrinol 6 (12): 944-953. doi: 10.1016/ s2213-8587(18)30288-2.

Bosch, X., E. Monclús, O. Escoda, M. Guerra-García, P. Moreno, N. Guasch, and A. López-Soto. 2017. "Unintentional Weight Loss: Clinical Characteristics and Outcomes in a Prospective Cohort of 2677 Patients." PLoS One 12 (4): e0175125. doi: 10.1371/journal.pone.0175125.

Bosello, O., and A. Vanzo. 2019. "Obesity Paradox and Aging." Eat Weight Disord. doi: 10.1007/s40519-019-00815-4.

Cao, Y., R. Hardy, and W. Wulaningsih. 2019. "Associations of Medical Conditions, Lifestyle and Unintentional Weight Loss in Early Old Age: The 1946 British Birth Cohort." PLoS One 14 (4): e0211952. doi: 10.1371/journal.pone.0211952.

Christmas, C., and N. Rogus-Pulia. 2019. "Swallowing Disorders in the Older Population." J Am Geriatr Soc 67 (12): 2643-2649. doi: 10.1111/jgs.16137.

Compston, J. E., A. Wyman, G. FitzGerald, J. D. Adachi, R. D. Chapurlat, C. Cooper, A. Díez-Pérez, S. H. Gehlbach, S. L. Greenspan, F. H. Hooven, A. Z. LaCroix, L. March, J. C. Netelenbos, J. W. Nieves, J. Pfeilschifter, M. Rossini, C. Roux, K. G. Saag, E. S. Siris, S. Silverman, N. B. Watts, and F. A. Anderson, Jr. 2016. "Increase in Fracture Risk Following Unintentional Weight Loss in Postmenopausal Women: The Global Longitudinal Study of Osteoporosis in Women." J Bone Miner Res 31 (7): 1466-72. doi: 10.1002/jbmr.2810.

DiMilia, P. R., A. C. Mittman, and J. A. Batsis. 2019. "Benefit-to-Risk Balance of Weight Loss Interventions in Older Adults with Obesity." Curr Diab Rep 19 (11): 114. doi: 10.1007/s11892-019-1249-8.

Gaddey, H. L., and K. Holder. 2014. "Unintentional Weight Loss in Older Adults." Am Fam Physician 89 (9): 718-22.

Jensen, M. D., D. H. Ryan, C. M. Apovian, J. D. Ard, A. G. Comuzzie, K. A. Donato, F. B. Hu, V. S. Hubbard, J. M. Jakicic, R. F. Kushner, C. M. Loria, B. E. Millen, C. A. Nonas, F. X. Pi-Sunyer, J. Stevens, V. J. Stevens, T. A. Wadden, B. M. Wolfe, and S. Z. Yanovski. 2014. "2013 AHA/ACC/TOS Guideline for the Management of Overweight and Obesity in Adults: A Report of the American College of Cardiology/ American Heart Association Task Force on Practice Guidelines and The Obesity Society." J Am Coll Cardiol 63 (25 Pt B): 2985-3023. doi: 10.1016/j.jacc.2013.11.004.
Kalichman, L., D. Alperovitch-Najenson, and I. Treger. 2016. "The Impact of Patient's Weight on Post-Stroke Rehabilitation." Disabil Rehabil 38 (17): 1684-90. doi: 10.3109/09638288.2015.1107640.

Kim, M., J. Kim, and C. W. Won. 2018. "Association Between Involuntary Weight Loss with Low Muscle Mass and Health-Related Quality of Life in CommunityDwelling Older Adults: Nationwide Surveys (KNHANES 2008-2011)." Exp Gerontol 106:39-45. doi: 10.1016/j. exger.2018.02.027.

Leslie, W., and C. Hankey. 2015. "Aging, Nutritional Status and Health." Healthcare (Basel) 3 (3): 648-58. doi: 10.3390/ healthcare3030648.

Nishioka, S., H. Wakabayashi, K. Maeda, H. Shamoto, Y. Taketani, J. Kayashita, and R. Momosaki. 2020. "Body Mass Index and Recovery of Activities of Daily Living in Older Patients with Femoral Fracture: An Analysis of a National Inpatient Database in Japan." Arch Gerontol Geriatr 87:104009. doi: 10.1016/j.archger.2020.104009.

Ritchie, C. S., J. L. Locher, D. L. Roth, T. McVie, P. Sawyer, and R. Allman. 2008. "Unintentional Weight Loss Predicts Decline in Activities of Daily Living Function and Lifespace Mobility over 4 Years among Community-Dwelling Older Adults." J Gerontol A Biol Sci Med Sci 63 (1): 67-75. doi: 10.1093/gerona/63.1.67.

Swan, K., R. Speyer, B. J. Heijnen, B. Wagg, and R. Cordier. 2015. "Living with Oropharyngeal Dysphagia: Effects of Bolus Modification on Health-Related Quality of Life--A Systematic Review." Qual Life Res 24 (10): 2447-56. doi: 10.1007/s11136-015-0990-y.

Tieland, M., C. van Dronkelaar, and Y. Boirie. 2019. "Sarcopenic Obesity in the ICU." Curr Opin Clin Nutr Metab Care 22 (2): 162-166. doi: 10.1097/mco.0000000000000547.

Toft-Petersen, A. P., J. Wulff, D. A. Harrison, M. Ostermann, M. Margarson, K. M. Rowan, and D. Dawson. 2018. "Exploring the Impact of Using Measured or Estimated Values for Height and Weight on the Relationship between BMI and Acute Hospital Mortality." J Crit Care 44:196-202. doi: 10.1016/j.jcrc.2017.11.021.

Wannamethee, S. G., A. G. Shaper, and L. Lennon. 2005. "Reasons for Intentional Weight Loss, Unintentional Weight Loss, and Mortality in Older Men." Arch Intern Med 165 (9): 1035-40. doi: 10.1001/archinte.165.9.1035. 